\title{
BANANA PSEUDO-STEM: AN ALTERNATIVE RAW MATERIAL FOR PAPER MAKING
}

\author{
Dr. Girish M. Deshmukh \\ Associate Professor and Head, \\ Department of Pulp and Paper Technology, \\ Laxminarayan Institute of Technology, \\ Nagpur, Maharashtra -440033
}

\begin{abstract}
This study deals with production of pulp and paper from waste banana pseudo stem and comparison with recycled pulp used for paper making. Banana pseudo stem was collected from local market of Nagpur and pulped at $120^{\circ} \mathrm{C}$ and atmospheric pressure. The pulp was reacted with peroxide to obtain bleached pulp by keeping in a thermostatically controlled water bath. The kappa number after bleaching was observed as 20.43 respectively. Beating of pulp was done in standard lab beater. Sheets were prepared by using pulp in different blending ratios. Burst factor for sheet prepared from virgin banana stem was observed as 30.04, higher than the sheet prepared from recycled pulp which showed burst factor of 18.84 Blending of banana pulp with recycled pulp (50\%:50\%) showed burst factor of 40.57 , which was quite impressive.
\end{abstract}

Keywords - Banana pseudo stem, Paper, Pulp, Bursting strength, Recycled pulp

\section{INTRODUCTION}

The utilization of pulp and paper products has increased tremendously during this modern era. Paper and paper products are used in various industries like packaging, pharmaceuticals, Fast moving consumer goods (FMCG). Paper today pervades almost all activities of man and it can be said without exaggeration that human activities will be severely affected if paper disappears. With the growing literacy and industrialization consumption of paper naturally rises. The main raw material for paper production is cellulose. Cellulose is obtained from forest raw materials like softwood, hardwood, bamboo etc. Due to the continuous utilization of these raw materials, scarcity of them is observed. Therefore, alternate raw materials are searched to replace the conventional raw materials. Also, the agricultural waste like bagasse, rice straw, wheat straw require high temperature and pressure conditions for pulping. Moreover, nowadays paper mills use recycled pulp as their raw material but it has various drawbacks like less strength properties, short fiber length etc. Therefore, in this study a new raw material is studied and experimented for paper production which can be pulped at low temperature and pressure conditions and is available as waste in nature. One such material which is used for this study is

\author{
Himanshu A. Sawarkar, Twinkle D. Varu \\ Research Assistants, \\ Department of Pulp and Paper Technology, \\ Laxminarayan Institute of Technology, \\ Nagpur, Maharashtra -440033
}

pseudo banana stem. Mohapatra et al (2010), Saika et al (1997) and Jayaprabha et al (2011) in their work emphasized on utilization of banana for production of paper and various product and its characteristics.

The production of banana in India is quite prominent. Its area under cultivation is second largest in India among the fruit crops. Due to the non-availability of suitable technology for its use, about 9.8 lakh tons of banana residues go to squander. This study not only consists of production of paper but also synthesis of banana pulp at low temperature and pressure conditions. The pulp is then subjected to bleaching operation and then required stock is prepared for preparation of sheets. Different ratios of pulp were taken to check different properties of sheets.

\section{EXPERIMENTAL WORK}

The experimental work includes preparation of raw material, proximate analysis, pulping, bleaching, stock preparation, sheet formation \& testing. Goswami et al (2008), Azahari et al (2016), Kumar et al (2011) and Khan et al (2013) emphasized and addressed different pulping and paper manufacturing methods. The method incorporated in this study is described below.

\section{A. Preparation of raw material-}

The raw material utilized for this experiment was waste pseudo banana stem as shown in Fig 1. It was collected from a local market in Nagpur, Maharashtra. Maharashtra is a principle banana producing state. The banana stem was chopped in a length of $4-5 \mathrm{~cm}$ and washed several times to remove any impurities present in it as shown in Fig 2.

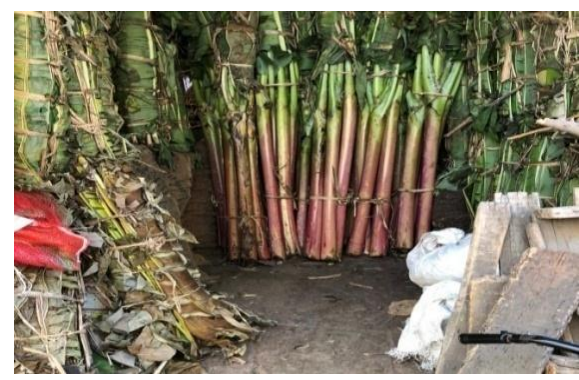




\section{International Journal of Engineering Applied Sciences and Technology, 2019 \\ Vol. 4, Issue 4, ISSN No. 2455-2143, Pages 68-73 \\ Published Online August 2019 in IJEAST (http://www.ijeast.com)}

Fig. 1. Collection of banana pseudo-stem

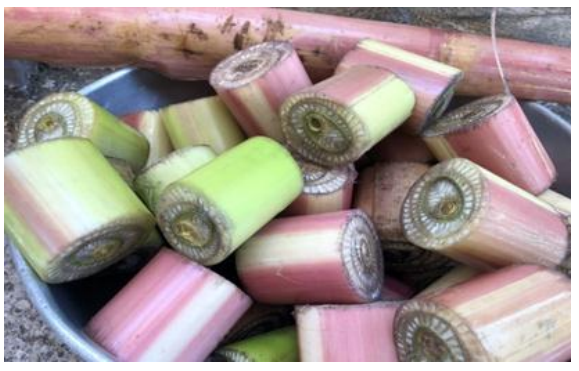

Fig. 2. Preparation of banana stem chips

It was kept in sunlight for next 2-3 days to remove moisture present in it. The sample was then oven dried and weighed. Subagyo et al (2018), poonam et al (1991), Li et al (2010) in their work emphasized on Chemical properties of banana fiber.

\section{B. Proximate analysis-}

Proximate analysis of pseudo banana stem was performed to find its chemical composition. All tests were performed according to TAPPI standards [6][13]. The moisture content was observed as $93.2 \%$ respectively. The lignin content was observed as $18.9 \%$ respectively. The extractives content was observed $8.7 \%$ respectively. The ash content was observed as $10.26 \%$ respectively. Holocellulose content was observed as $58.94 \%$ respectively. $1 \% \mathrm{NaOH}$ solubility was observed as $30 \%$ respectively.

\section{Pulping-}

The foremost goal of pulping is delignification. The sample was pulped using kraft pulping. In this method cooking liquor was prepared using kraft pulping chemicals in the following proportion.

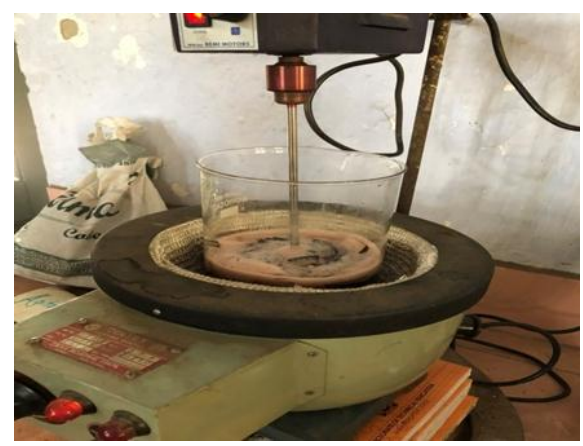

Fig. 3. Pulping apparatus

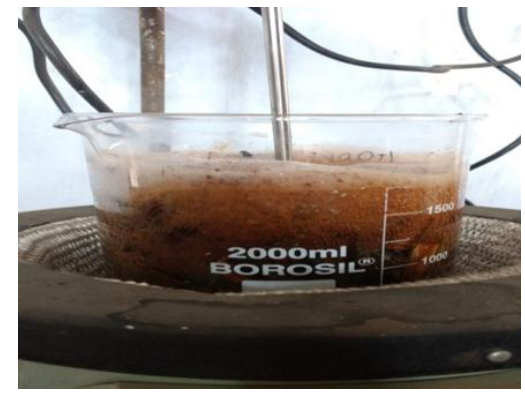

Fig. 4. Pulping of banana pseudo-stem

Kraft chemicals were taken to make $12.5 \%$ by weight solution. It consists of $58.65 \% \mathrm{NaOH}, 27.04 \% \mathrm{Na}_{2} \mathrm{SO}_{4}$, and $14.31 \% \mathrm{Na}_{2} \mathrm{CO}_{3}$. The prepared liquor was added to sample until chips were partially submerged in it. The system was then heated at $120^{\circ} \mathrm{C}$ for a period of $1.5-2$ hours. Continuous agitation was provided with the help of agitator as shown in Fig $3 \& 4$.

\section{Bleaching-}

Bleaching was done to whiten the pulp and remove residual lignin present in it. The bleaching liquor consisted $85 \% \mathrm{H}_{2} \mathrm{O}_{2}$, $10 \%$ Pulp, $4 \% \mathrm{MgSO}_{4}$ and $1 \% \mathrm{CaCO}_{3}$. The liquor containing pulp was transferred to a plastic bag $(<50$ microns $)$ and packed tightly as shown in Fig 5.

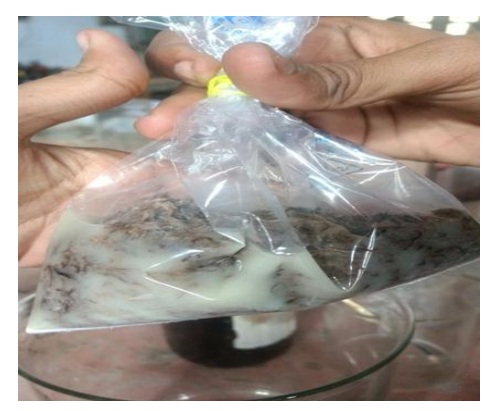

Fig. 5. Bleaching of pulp

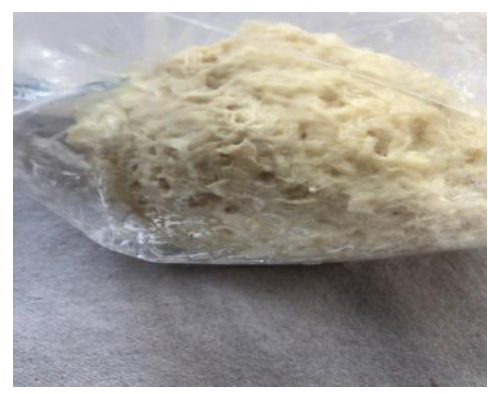

Fig. 6. Bleached Pulp 


\section{International Journal of Engineering Applied Sciences and Technology, 2019 \\ Vol. 4, Issue 4, ISSN No. 2455-2143, Pages 68-73 \\ Published Online August 2019 in IJEAST (http://www.ijeast.com)}

The system was kept in a double water bath to ensure a temperature of $60-65^{\circ} \mathrm{C}$ and heated for 45 minutes. After 45 minutes white color of pulp was observed as shown in Fig 6. The pulp was then washed and dried for further processing.

\section{E. Stock preparation \& Sheet formation-}

The pulp obtained after washing, bleaching is still not ready for sheet formation. It must undergo some mechanical operation to impart several characteristics which are required in different grades of paper. Beating of banana pulp was performed in the lab beater. The pulp was loaded in the lab beater as shown in Fig 7. Water was added in it while maintaining the consistency. The beating was done for a period of 20 minutes. Fillers like starch and calcium carbonate were added while beating to improve surface properties.

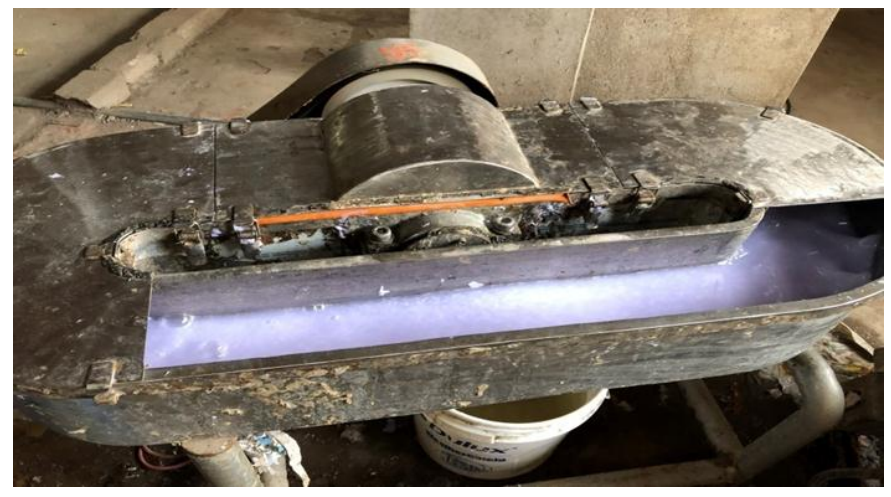

Fig. 7. Laboratory beater

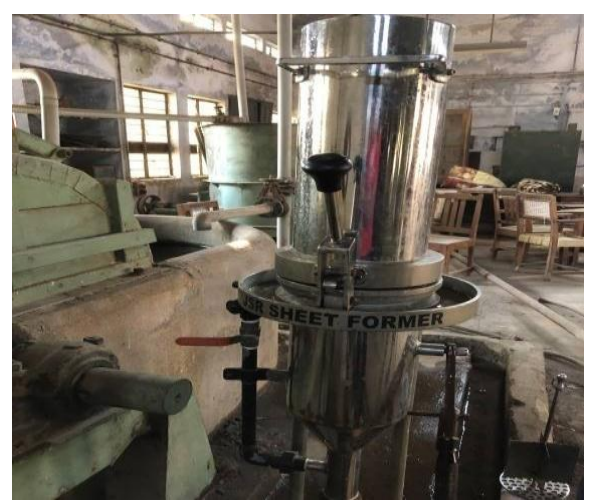

Fig. 8. Sheet Former

For the formation of sheets, lab sheet former was used as shown in Fig 8. Stock was prepared according to the different types of sheets to be formed. TYPE 1 sheet was prepared from $100 \%$ virgin banana pulp, TYPE 2 was prepared from $100 \%$ recycled pulp of waste paper and TYPE 3 sheet was prepared from $50-50 \%$ of virgin and recycled pulp respectively.

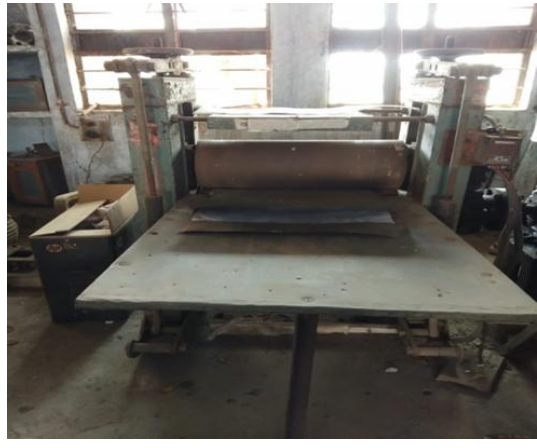

Fig. 9. Calendering

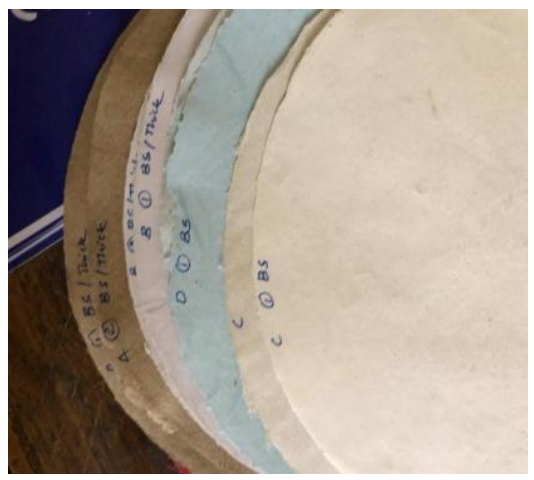

Fig. 10. Different types of sheets produced

After the sheet was prepared it was pressed and dried for further testing. Calendaring operation was done to impart smoothness as shown in Fig 9. Different types of sheet formed are shown in Fig 10.

\section{MATERIAL BALANCE AND FLOWCHART}

Material balance for different unit operations performed during this experiment to find yield of the product. Material balance for digestion and bleaching are explained below.

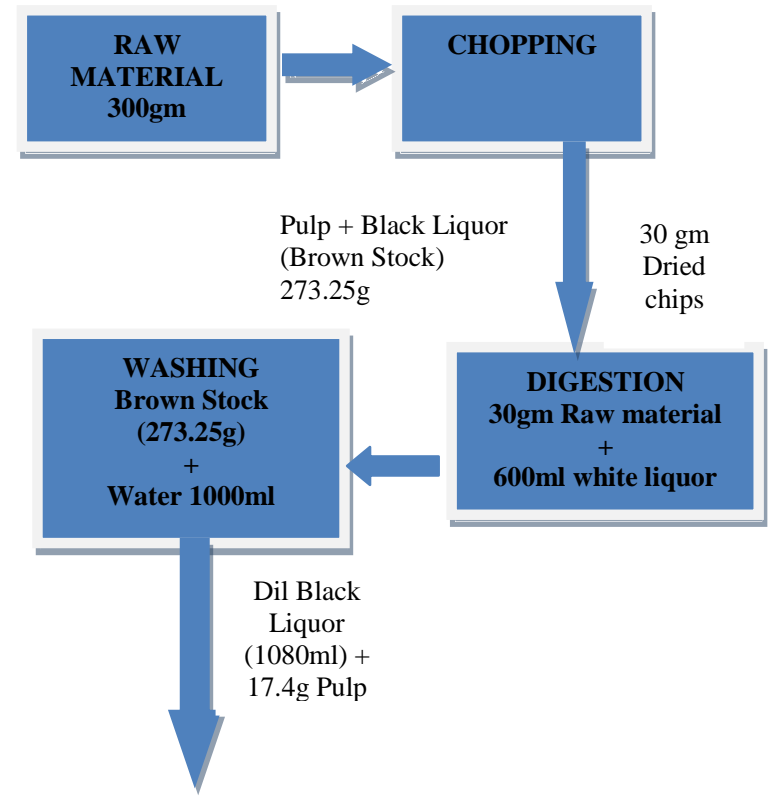




\section{International Journal of Engineering Applied Sciences and Technology, 2019 \\ Vol. 4, Issue 4, ISSN No. 2455-2143, Pages 68-73 \\ Published Online August 2019 in IJEAST (http://www.ijeast.com)}

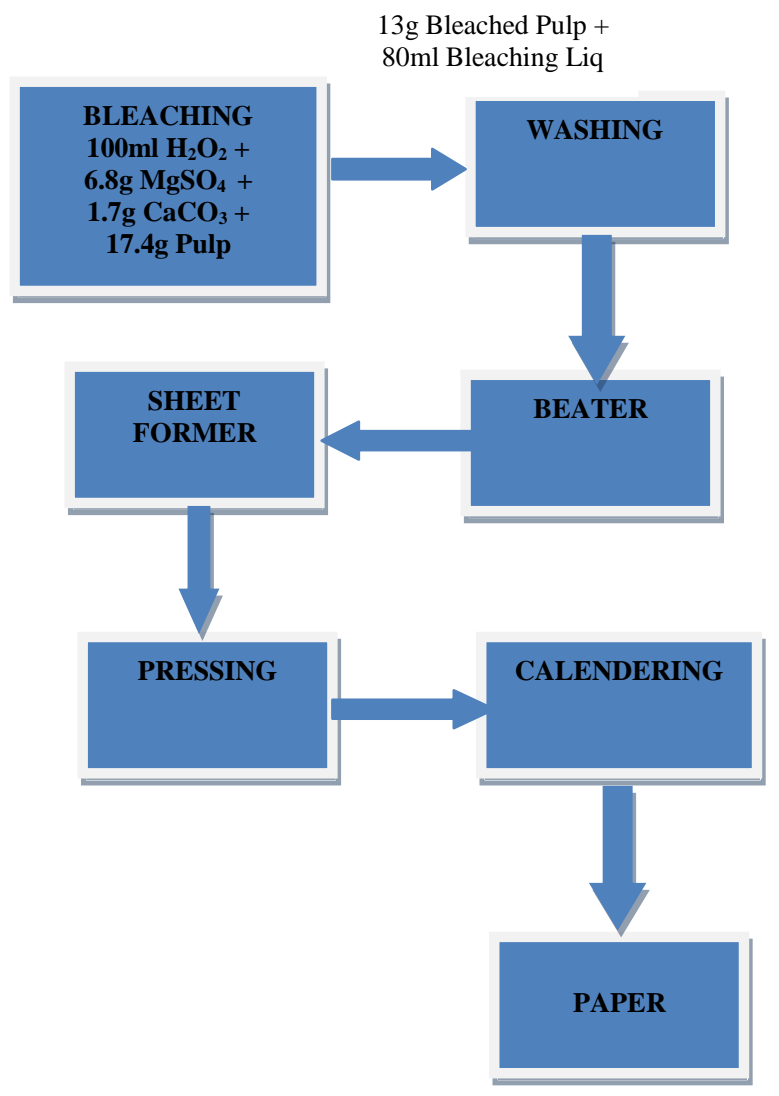

Fig. 11. Flowchart of Process

\section{A. Digestion-}

BASIS: 30 gm of Banana stem chips

30 gm of banana pseudo stem chips after cutting and washing were sent to the pulping system along with $600 \mathrm{ml}$ cooking liquor. It was cooked for 2 hours at $120^{\circ} \mathrm{C}$. The brown stock obtained after pulping is sent to washer. The brown stock mainly consists of cellulosic fibers and black liquor. To separate the fibers from black liquor the pulp is washed number of times. The weight obtained after pulping, washing and drying was $17.4 \mathrm{gm}$. Therefore,

$$
\begin{aligned}
\text { Yield of pulp } & =\frac{17.4}{30} \times 100 \\
& =58 \%
\end{aligned}
$$

\section{B. Bleaching-}

BASIS: $17.4 \mathrm{gm}$

The bleaching process performed in this experiment is total chlorine free process which is peroxide bleaching. Bleaching is performed to remove residual lignin content and whiten the pulp. The weight obtained after bleaching, washing and drying was $13 \mathrm{gm}$. Therefore,

$$
\begin{aligned}
\text { Yield of pulp } & =\frac{13}{30} \times 100 \\
& =43.33 \%
\end{aligned}
$$

The entire process of operation is shown in Fig 11.

\section{RESULT \& DISCUSSION}

After experimenting and testing entire process following results were declared. All tests were performed according to the TAPPI standards et al (1980).

\section{A. Analysis of pulp-}

Pulp prepared from pulping of banana pseudo stem and its bleaching was analyzed. After testing, kappa number was observed as 20.43 respectively. $1 \%, 10 \%$ and $18 \% \mathrm{NaOH}$ solubility were observed as $6.66 \%, 14.82 \%$ and $48.27 \%$ respectively.

\section{B. Analysis of black liquor-}

Black liquor obtained after pulping was analyzed. Solid content of black liquor was observed as $28.65 \%$ respectively. The $\mathrm{pH}$ of black liquor was observed as 12 respectively.

\section{Yield of pulp-}

The yield calculated after pulping and bleaching was observed as $58 \%$ for unbleached pulp and $43.33 \%$ for bleached pulp respectively. Andreasson et al (2003) emphasized in their work different yields and its influence on paper strength.

\section{Testing of Paper-}

Sheet formed from different blends of pulp were tested to obtain different physical properties as shown in Table 1.

Table -1 Testing of physical properties of sheets

\begin{tabular}{|l|l|l|l|}
\hline TEST & $\begin{array}{l}\text { TYPE } \\
\mathbf{1}\end{array}$ & $\begin{array}{l}\text { TYPE } \\
\mathbf{2}\end{array}$ & $\begin{array}{l}\text { TYPE } \\
\mathbf{3}\end{array}$ \\
\hline GSM & 213 & 240 & 138 \\
\hline $\begin{array}{l}\text { Bursting } \\
\text { Strength } \\
\left(\mathrm{Kg} / \mathrm{cm}^{2}\right)\end{array}$ & 6.4 & 2.6 & 5.6 \\
\hline Burst Factor & 30.04 & 18.84 & 40.57 \\
\hline Burst Index $(\mathrm{kPa} / \mathrm{g})$ & 2.9466 & 1.06 & 4.3 \\
\hline
\end{tabular}

E. Comparison of physical properties of sheets-

Comparison of physical strength properties for different type of sheet prepared were made to find the better one. From the graph as shown in Fig 12,13 \& 14 it was observed that the bursting properties of recycled paper is least, however bursting property increased when banana pulp was blended with recycled one. Bursting strength is defined as the hydrostatic 


\section{International Journal of Engineering Applied Sciences and Technology, 2019 \\ Vol. 4, Issue 4, ISSN No. 2455-2143, Pages 68-73 \\ Published Online August 2019 in IJEAST (http://www.ijeast.com)}

pressure in kilopascals or kilo Newton's per square meter required to produce rupture of the material when the pressure is increased at a controlled constant rate through a rubber diaphragm to circular area, $30.5 \mathrm{~mm}$ diam. The area of the material under test is initially flat and held rigidly at the circumference but free to bulge during the test. Also, it was compared with the work of Khan et al (2008).

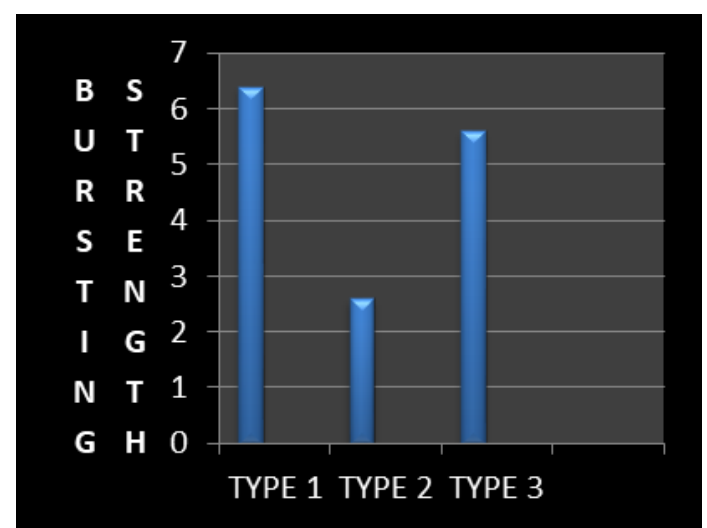

Fig. 12. Comparison of bursting strength of TYPE 1, TYPE 2 and TYPE 3 Sheets

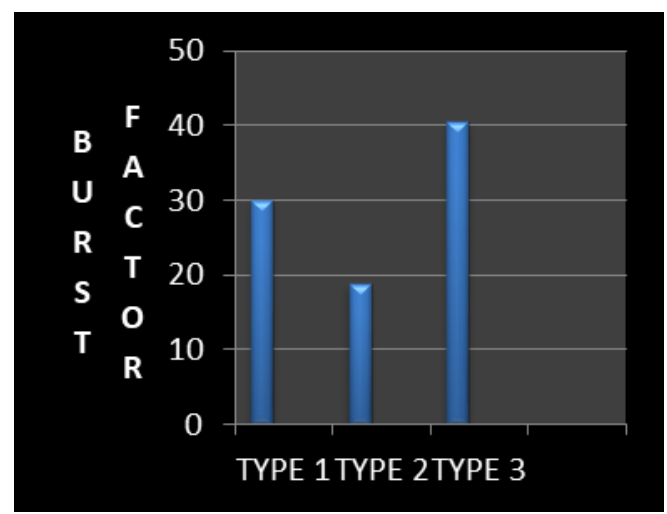

Fig. 13. Comparison of burst factor of TYPE 1, TYPE 2 and TYPE 3 Sheets

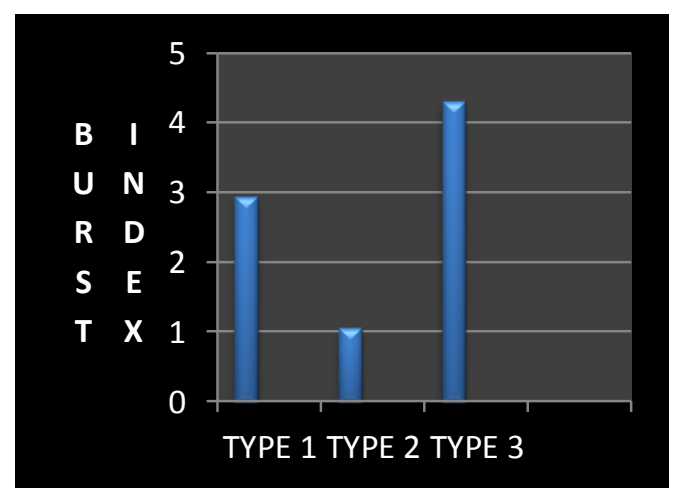

Fig. 14. Comparison of burst index of TYPE 1, TYPE 2 and TYPE 3 Sheets
Thus, we can say that by blending banana pulp with recycled one we can increase the strength of paper. Banana pulp is therefore advantageous for any paper where high strength is required like packaging paper.

\section{CONCLUSION}

The pulp was successfully prepared from waste banana stem with the yield of $58 \%$ before bleaching and $43.33 \%$ after bleaching. The sample was pulped at condition of $120^{\circ} \mathrm{C}$ and atmospheric pressure which is much less than the industrially used condition of $170^{\circ} \mathrm{C}$ and $7 \mathrm{~atm}$ pressure for conventional raw materials in kraft pulping process. Here sheets were prepared using different blends of virgin banana pulp and university cuttings recycled paper. Type 1 consists of $100 \%$ virgin banana pulp with burst factor of 30.04. Type 2 consists of $100 \%$ recycled pulp with burst factor of 18.84 . Type 3 consists of $50 \%$ virgin banana plus $50 \%$ recycled pulp with burst factor of 40.57. It can be observed that, type 1 sheet has higher bursting strength than type 2 which implies that sheet made from banana fibers has more strength than the recycled pulp sheet. Also, when blending of banana fibers was done with recycled it gave improved strength characteristics. Therefore banana fibers can be used for making high strength as compared with recycled paper. The only drawback is its high moisture content. Cultivating banana near mill areas can be the solution. From the above made conclusions, banana pseudo stem can be proved as an potential alternative raw material for paper industries.

\section{ACKNOWLEDGMENT}

The authors would like to express hearty gratitude and thankfulness to the Department of Pulp and Paper technology (Chemical Technology), Laxminarayan Institute of Technology, RTM Nagpur University for the facilities to do this study. We are equally grateful to the entire staff of LIT for helping us and sharing their experiences.

\section{REFERENCE}

1) Goswami T, Kalita D*, \& P G Rao,(2008), Greaseproof paper from Banana (Musa paradisica L.) pulp fiber, North East Institute of Science and Technology (CSIR), Indian journal of chemical technology vol. 15, pp 457-461

2) Khan M. Z H, Sarkar M.A.R., Forhadibne Al Inam, Khan M. Zahid H. \& Malien Raimo O.(2008), Paper Making from Banana PseudoStem: Characterization and Comparison, Journal of Natural Fibers, 11(3): pp 199-211

3) Andreasson B, Forsstrom J., Wagberg L, (2003), The porous structure of pulp fibers with different yields and its influence on paper strength. 
Cellulose 10(2): pp 111-123

4) Mohapatra D., Mishra S and Sutar N, (2010), Banana and its Byproduct utilization, Journal of scientific and industrial research , 69(5): pp 323329

5) Azahari B, Fattah N.A., Bakkan A. A, Ariff Z. M., (2016), Production of laminated natural fiber board from banana tree waste, DOI 10.1016/j.proche.2016.03.149

6) Poonam B., and Gupta K.C., (1991), PhysioChemical properties of banana fiber, Indian textile journal 2: pp 60-62

7) Saikia D. C., (1997), Wild banana plants (musa spp) as source of fiber for paper and cordage industries, Journal of Science and industrial research, 56(7): 408-413

8) Kumar M., and Kumar D, (2011), Comparative study of pulping of banana stem, International journal of fiber and textile research, 1(1): pp 1-5

9) Subagyo. A , and Chafidz A, (2018), Banana Pseudo- Stem fiber: preparation, Characteristics and applications, DOI 10.5772/intechopen.82204

10) Jayaprabha J. S., Brahmakumar M., and Vattackatt M. B., (2011), Banana pseudo stem characterization and its fiber property evaluation on physical and bioextraction, $10.1080 / 15440478.2011 .601614$

11) Khan, S., Imam, F., and Malinen, R. (2013), Fiber morphology and Pulping study of Banana Pseudostem, International Journal of Fiber and Textile Research, 3(1): pp31-35

12) Li K., Fu. S., Zhan, H., Zhan, Y., and Lucia,( 2010), Banana Pseudo-stem Chemistry, Structure, BioResources, Volume 5, No. 2, pp 576-588

13) TAPPI (Technical Association of the Pulp and Paper Industry), (1980), 'Standard and Suggested Methods Technical Association of Pulp and Paper Industries', New York, Volume 2, No. 1, pp 14-19 